\title{
Noise Optimization of Low Power CMOS Charge Amplifier Using Simulation Environment of Eldo ${ }^{\mathrm{TM}}$
}

\author{
Shahzad Naseem ${ }^{1}$, Saira Riaz ${ }^{1}$, M. Altaf Hussain ${ }^{1}$ and M. Ghayas-Udin ${ }^{2}$ \\ ${ }^{1}$ Microelectronics Division, Centre of Excellence in Solid State Physics, University of the Punjab, QAC, Lahore-54590, Pakistan \\ ${ }^{2}$ National Institute of Electronics, Islamabad \\ shahzadnaseem@yahoo.com
}

\begin{abstract}
A CMOS charge amplifier, due to its very low power consumption and good noise performance, has great interest for analog signal processing in the fields of particle physics, nuclear physics and $\mathrm{x}$ - or beta-ray detection. The simulation environment of Eldo $^{\mathrm{TM}}$ using AMI05 (American Microsystems Inc.) technology provided by Mentor Graphics Corporation is used for noise optimization of a low power CMOS charge amplifier. Using simulation tools we have designed and simulated the output of the charge amplifier and have calculated the power consumption, band width, gain and Equivalent Noise Charge (ENC) of the circuit. We have also studied the factors on which noise of amplifier depends. This has resulted in a noise performance of $\mathrm{ENC}=116$ electrons at 0 $\mathrm{pF}$ detector capacitance with a power consumption of $80 \mu \mathrm{W}$ per channel. Due to its very low noise and low power consumption, this kind of new charge amplifier can be widely used in research in the fields of Particle Physics, Nuclear Physics and X-ray detection.
\end{abstract}

Index Terms - CMOS, mentor graphics, Eldo ${ }^{\mathrm{TM}}$, low power

\section{Introduction}

Basically a CMOS charge amplifier is a charge-to-voltage converter, because it converts an input charge signal into output voltage signal. It acts as an amplifier whose equivalent input impedance is a capacitive reactance that is very high at low frequencies. A CMOS charge amplifier does not amplify the electric charge present at its input. Its function is actually to obtain a voltage proportional to that charge and yields low output impedance. Hence it is called a charge to voltage converter.

When a semiconductor detector (a device used to detect or locate the presence of radiations, particles etc.) such as Si used for the measurement of low to high-energy gamma rays and soft X-rays, the output signal is a very weak charge pulse having pulse width of several tens of nanosecond, therefore a preamplifier must be required to amplification of this weak output signal ${ }^{1}$.

The total noise contribution of the amplifier is mainly determined by the input transistor ${ }^{2}$. The input transistor is the main device which tunes the noise; the contributions of the other transistors cannot be completely neglected though. The dimension of these transistors has therefore been optimized with respect to their noise behavior ${ }^{3}$. The choice of the input transistor as well as its bias current is very important. Normally the noise performance of the input transistor is mainly characterized by an equivalent input noise voltage source $\mathrm{V}_{\mathrm{e}}$ with noise spectral density (equivalent input noise voltage source $)^{2}$.
$\mathrm{Hu}$ et $\mathrm{al}^{4}{ }^{4}$ reported the (ENC) noise performance of 343 electrons at $0 \mathrm{pF}$ with a noise slope of 28 electrons $/ \mathrm{pF}$ for a peaking time of $10 \mu \mathrm{s}$. A $37 \mathrm{mV} / \mathrm{fC}$ conversion gain, $3.5 \mathrm{~V}$ power supply and $150 \mu \mathrm{W} /$ channel power consumption was obtained. Nygard et al. ${ }^{5}$ reported ENC of 112 electrons at $0 \mathrm{pF}$ with a slope of 34 electrons $/ \mathrm{pF}$ for a power consumption of $1 \mathrm{~mW}$. Hu et al. ${ }^{6}$ reported theoretical results that show a total output noise voltage reduction of $0.264 \mathrm{mV}$. A measured noise performance of 450 electrons at $0 \mathrm{pF}$ with a slope of $45 \mathrm{~ns}$, a conversion gain of $20 \mathrm{mV} / \mathrm{fC}$ and $1 \mathrm{~mW}$ power consumption was obtained. Berst et al. ${ }^{7}$ presented a noise performance of $\mathrm{ENC}=330 \mathrm{e}^{-}+51 \mathrm{e}^{-} / \mathrm{pF}$ for a peaking time of $100 \mathrm{~ns}$. The simulations were performed for the devices to be used in future LHC experiments, and an ENC noise slope of 37 electrons $/ \mathrm{pF}$ has been obtained, with power consumption of $1 \mathrm{~mW}$ per channel for shaping time of $25 \mathrm{~ns}^{8}$.

We have designed a schematic of CMOS Charge Amplifier and have run on Eldo ${ }^{\mathrm{TM}}$ Simulator and then checked its behavior on EZ-waves by using IC Nanometer Design software (designed by Mentor Graphics Corporation). The following three important key points were kept in mind that can improve the low noise, tranconductance, speed of amplifier and flicker noise.

- The dimensions of input transistor act as a key by which we control the noise of charge-amplifier.

- The FET on the output must be small in order to realize high speed of charge amplifier.

- In order to minimize the intrinsic noise, a PMOS transistor has been chosen as input transistor due to its lower flicker noise compared to the corresponding NMOS transistor.

\section{Results and Discussion}

Most important parameters and constants that have been selected for these simulations are summarized in Table.1.

By using the design architect graphics and tools and by following the important points explained above, we created a schematic capture of CMOS charge amplifier circuit as shown in Figure 1. By using AMI05 technology, Transient Analysis result obtained is shown in Figure 2. 
Table.1. Charge Amplifier Design Parameters and Constants

\begin{tabular}{|l|l|l|}
\hline Symbol & Description & Selected Values \\
\hline $\mathrm{W} / \mathrm{L}$ & Input transistor $\left(\mathrm{T}_{1}\right)$ dimension & $1000 \mu \mathrm{m} / 0.25 \mu \mathrm{m}$ \\
\hline $\mathrm{C}_{\mathrm{f}}$ & Feedback capacitance & $0.6 \mathrm{pF}$ \\
\hline $\mathrm{C}_{\mathrm{i}}$ & Input capacitance & $78.73 \mathrm{pF}$ \\
\hline $\mathrm{C}_{\mathrm{d}}$ & Detector capacitance & $0 \mathrm{pF}$ \\
\hline $\mathrm{V}_{\mathrm{DD}} \& \mathrm{~V}_{\mathrm{SS}}$ & Power supply & $\mathrm{V}_{\mathrm{DD}}=+2 \mathrm{~V}, \mathrm{~V}_{\mathrm{SS}}=-$ \\
\hline $\mathrm{I}_{\mathrm{d}}$ & Bias current & $2 \mathrm{~V}$ \\
\hline $\mathrm{K}_{\mathrm{f}}$ & Flicker noise coefficient & $20 \mu \mathrm{A}$ \\
\hline $\mathrm{C}_{\mathrm{ox}}$ & Oxide capacitance & $6.4 \mathrm{fF} / \mu \mathrm{m}^{2}$ \\
\hline $\mathrm{K}$ & Stefan-Boltzmann constant & $1.38 \mathrm{~m} 10^{-23} \mathrm{~J} . \mathrm{K}^{-1}$ \\
\hline $\mathrm{T}$ & Absolute temperature & $300 \mathrm{~K}$ \\
\hline $\mathrm{K}_{\mathrm{P}}$ & Transconductance constant & $6.42 \times 10^{-7} \mathrm{~A} / \mathrm{V}^{2}$ \\
\hline $\mathrm{Q}_{\mathrm{in}}$ & Input current pulse & $22000 \mathrm{e}^{-} \mathrm{or} 3.52 \mathrm{fC}$ \\
\hline $\mathrm{g}_{\mathrm{m}}$ & Transconductance constant & $0.315 \mathrm{~mA} / \mathrm{V}$ \\
\hline $\mathrm{R}_{\mathrm{f}}$ & Feedback resistance & $\sim 48 \mathrm{M} \Omega$ \\
\hline & & \\
\hline
\end{tabular}

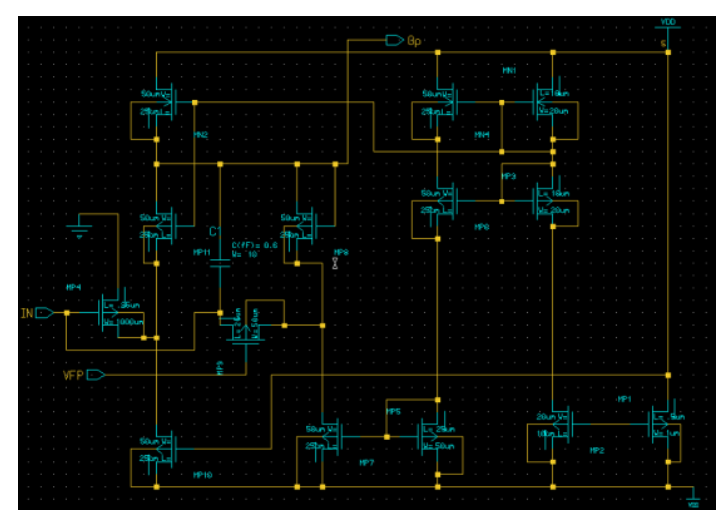

Fig.1. Schematic of CMOS Charge Amplifier Circuit

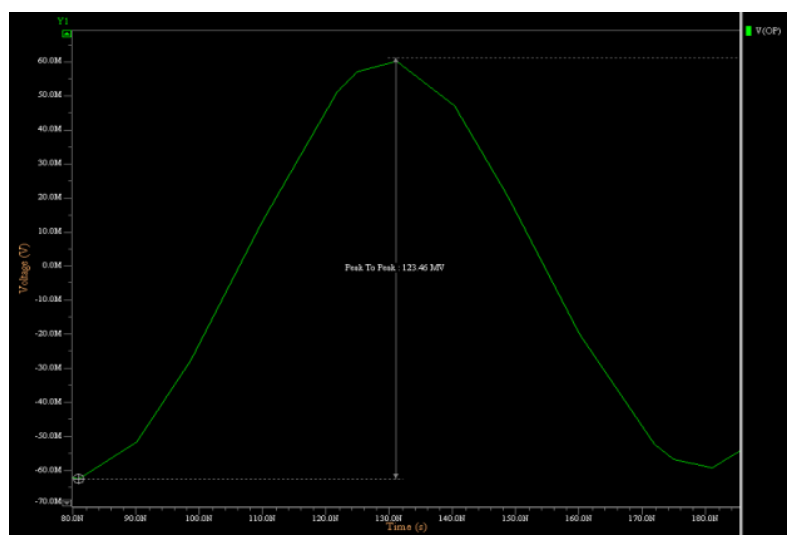

Fig.2. Transient Analysis result, using AMI05 Technology

Our designed charge amplifier circuit is an analog amplifier circuit as can be seen from the shape of the curve in this figure. From Figure 2, we obtain peak-to-peak voltage of Vout $=123 \mathrm{mV}$. Vout calculated here along with Table. 1 can be used to arrive at:

$$
\mathrm{A}_{\mathrm{qv}}=34.94 \mathrm{mV} / \mathrm{fC}
$$

Now we also find the voltage gain $\left(\mathrm{A}_{\mathrm{v}}\right)$ of charge amplifier that comes out to be $A_{v}=0.2469$. As $V_{\text {in }}>V_{\text {out }}$ and $A_{v}<1$ (i.e. output voltage of signal reduced from input voltage of signal, so it is a power amplifier which increase the power of weak input signal.

By using AMI05 technology, AC-Analysis result is obtained as shown in Figure 3. Our designed circuit behaves like a low-pass filter circuit. Cutoff frequency $\left(\mathrm{W}_{\mathrm{c}}\right)$ is the frequency at which voltage gain is equal $A_{v}=0.707$ of maximum value.

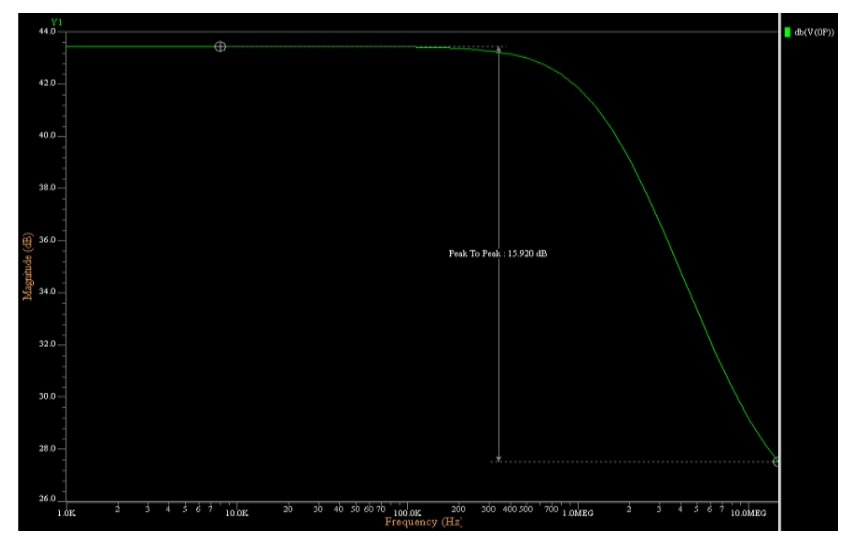

Fig. 3 . AC - Analysis result, using ami05 Technology

From Fig. 3:

Cutoff frequency $\left(\mathrm{W}_{\mathrm{c}}\right)$ $=900 \mathrm{kHz}$

Lower cutoff frequency $\left(\mathrm{f}_{1}\right)$

Band width $(\mathrm{BW}) \quad=899 \mathrm{kHz}$

We calculated the values of spectral density (Svn) corresponding to different frequency values and plotted these, as shown in Figure 4.

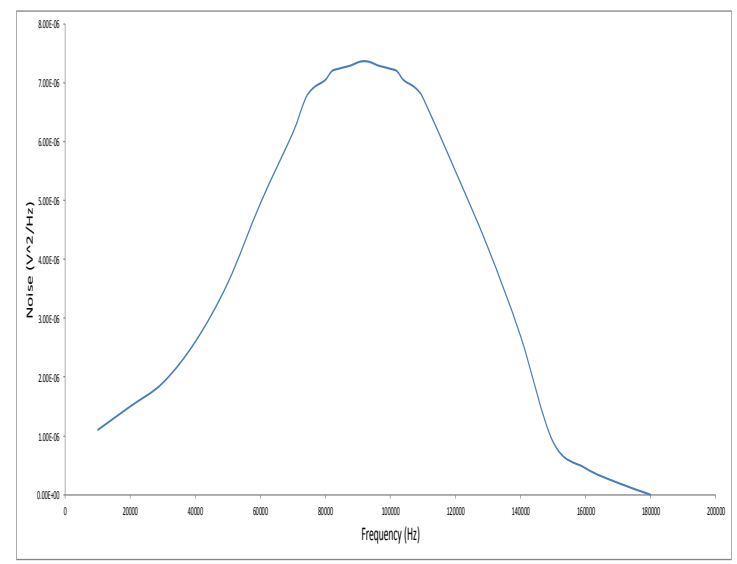

Fig. 4. Output noise spectral density 
As the optimized noise performance is present in Figure 4 from which we obtained system noise band width $\Delta \mathrm{f}=63 \mathrm{kHz}$ by which the total rms output noise voltage $V_{n}$ total is calculated.

From the values in Table 1 and using various standard equations, we get the resultant values for our designed charge amplifier. These values are summarized in Table 2 below.

Table.2. Eldo ${ }^{\mathrm{TM}}$ simulation results summary for a CMOS charge Amplifier (using ami05 technology)

\begin{tabular}{|l|l|}
\hline \multicolumn{1}{|c|}{ Power supply } & VDD $=+\mathbf{2 V}, \mathbf{V S S}=\mathbf{- 2 V}$ \\
\hline Bias current (Ids) & $20 \mu \mathrm{A}$ \\
\hline Power consumption (p) & $80 \mu \mathrm{W}$ \\
\hline Tranconductance (gm) & $0.315 \mathrm{~mA} / \mathrm{V}$ \\
\hline Conversion gain (Aqv) & $34.94 \mathrm{mV} / \mathrm{fC}$ \\
\hline Equivalent Noise Charge (ENC) & $116 \mathrm{e}-$ at Cd $=0 \mathrm{pF}$ \\
\hline Voltage gain (Av) & 0.247 \\
\hline Cutoff frequency (Wc) & $900 \mathrm{kHz}$ \\
\hline Band width (BW) & $899 \mathrm{kHz}$ \\
\hline Input current pulse (Qin) & $22000 \mathrm{e}-$ or $3.52 \mathrm{fC}$ \\
\hline
\end{tabular}

\section{Conclusions}

In this work, noise optimization of low power CMOS charge amplifier using simulation environment of Eldo ${ }^{\mathrm{TM}}$ has been presented. Simulation results show that a noise performance $(\mathrm{ENC})$ of this charge amplifier is $\mathrm{ENC}=116$ electrons at $0 \mathrm{pF}$ detector capacitance has been obtained with a power consumption of $80 \mu \mathrm{W}$ per channel. Due to its very low noise and low power consumption, this kind of charge amplifier can be widely used in particle physics, nuclear physics and x-ray detection.

\section{Acknowledgments}

This work was supported Higher Education Commission (HEC), Pakistan under Grant given to COE in Solid State Physics and National Institute of Electronics, Islamabad.

\section{References}

[1] B.L. Theraja, Basic Electronics - Solid State, S Chand \& Company LRD, India (1997)

[2] B.G. Streetman and S.K. Banerjee, Solid State Electronic Devices, Pearson Prentice Hall, USA (2007)

[3] Y. Hu, J. D. Berst and M. Schaeffer, Analog. Integ. Circ. Sign. Process., 17,249 (1998)

[4] Y. Hu and E. Nygard, Nucl. Instrum. Meth. Phys. Res. A 365, 193 (1995)

[5] E. Nygard, P. Aspell, P. Jarron, P. Weilhammer and K. Yoshioka, European Organization for Nuclear Research CERN-PPE/90 (1990)

[6] Y. Hu, J. L. Solere, D. Lachartre and R. Turchetta, IEEE Trans. Nucl. Sci. 45, 1 (1998)

[7] J. D. Berst, W. Dulinski and Y. Hu, Nucl. Instrum. Meth. Phys. A 378, 589 (1996)

[8] A. Loge, W. Dulinski and Y. Hu, Nucl. Instrum. Meth. Phys. Res. A 423, $272(1998)$ 